\title{
Act without Fear or Favor: Ethics in Dentistry
}

\author{
${ }^{1}$ Vijaylaxmi Ramdurg, ${ }^{2}$ Praveenkumar Ramdurg
}

\begin{abstract}
The dental profession holds a special position of trust within society. As a consequence, society affords the profession certain privileges that are not available to members of the public at large. In return, the profession makes a commitment to society that its members will adhere to high ethical standards of conduct. A philosophical study of moral issues of right and wrong is called ethics, and deals with the moral duties of the professional dentists toward their patient, society and professional colleagues. The dentists have a duty to conduct their professional life, in accordance with the fundamental principles of ethics. This article reviews the evolution and philosophy of ethics, theories of ethics and the fundamental principles of ethics that the dentist should follow.
\end{abstract}

Keywords: Ethics, Theories of ethics, Philosophy, Autonomy, Justice.

How to cite this article: Ramdurg V, Ramdurg P. Act without Fear or Favor: Ethics in Dentistry. J Postgrad Med Edu Res 2014;48(4):186-189.

\section{Source of support: Nil}

Conflict of interest: None

\section{INTRODUCTION}

The dental profession is a vocation in which knowledge and skill is used for the service of others. As in many other healthcare fields, dentistry has undergone many changes in recent years. With new developments in areas, such as technology, equipment and materials, policies in managed care, third-party payment and infection control requirements as well as a rise in litigation, there are many new challenges for the private practitioner. One of the characteristics of a profession is adherence to a code of ethics. Being a healthcare provider, it carries with it a responsibility to individual patient and society. The special status that society confers on the professional requires them to behave in an ethical manner.

The word ethics comes from the Greek word 'ethos' originally meaning character or conduct. It is typically

\footnotetext{
${ }^{1}$ Senior Lecturer, ${ }^{2}$ Assistant Professor

${ }^{1}$ Department of Orthodontics, PMNM Dental College and Hospital, Bagalkote, Karnataka, India

${ }^{2}$ Department of Oral Medicine and Radiology, PMNM Dental College and Hospital, Bagalkote, Karnataka, India
}

Corresponding Author: Vijaylaxmi Ramdurg, Senior Lecturer Department of Orthodontics, PMNM Dental College and Hospital, Bagalkote, Karnataka, India, Phone: 8861593975 e-mail: praveenod@gmail.com used interchangeably with the word moral which is derived from the Latin word 'mores', which means customs or habits. Together these two terms refer to conduct, character and motivations involved in moral acts. ${ }^{1}$ Thus, ethics are not imposed by a profession or by law, but by moral obligation. Ethics are an unwritten code of conduct that encompasses both professional conduct and judgment. Though the details of the written ethical code may vary from profession to profession, the underlying principles of ethics remain the same.

Ethics is that branch of discipline of philosophy that studies morality. It is the 'science' of moral. ${ }^{2}$

As David T Ozar and David J Sokol suggest in Dental Ethics at Chairside: Professional Principles and Practical Applications, the ethical issues faced by dentists in today's society have become more complex and seem to arise more often than those faced by dentists in the past. Given the current direction of health and dental care, it is essential that dental professionals understand and practice wholeheartedly. ${ }^{3}$

As dentistry moves into the 21st century, the attention to ethics will have to be even greater. Nowadays, ethical standards in modern dentistry are in a tempo of rapid advance. However despite the significant growth of ethics in dental literature, dental ethics as a field of study and as a subdiscipline within the study of moral theories and principles of professional ethics is underdeveloped and analysis of dentally related ethical problems and application of ethical theories to them is still a young field. ${ }^{4}$

\section{EVOLUTION AND PHILOSOPHY OF ETHICS}

The original ethical concept was based upon mysticism. Tracing the history of ethics, it has been progressing gradually into the world of mystery which speculates on the unknown. Subsequently, people started accumulating and recording knowledge based on their facts. In the history of Egypt and Babylonia, people were interested in their destiny and belief in life hereafter. The Egyptian 'Book of the Dead', dated 3500 BC, describes immortality of the soul and lists behavior conductive to a desirable destiny. Prior to 1000 BC, India produced the 'Vedas'. Among expanded versions of Vedas were the 'Upanishads', Which were remarkable for their discourses on many problems, such as ethics, God, death and immortality.

In $470 \mathrm{BC}$, Greek philosophy evolved. According to philosophers like Aristotle, Plato, Socrates, one's action 
was either right or wrong, based entirely on the philosophy of individual's group. They follow one code for all.

During the middle ages, philosophy and religion, united by a common ethical interest, transferred old theories to a new setting. Individuals were recognized as Christian, and scientific discoveries sparked the revival of learning.

The 19th century was, generally, a time of equality and plenty for all and the scientific theories become more pronounced during these years. The twentieth century brought a great variety of moral beliefs, allowing a freedom in which each man could select his own values. ${ }^{1}$

\section{DENTISTRY AS A REFLECTION OF MEDICINE}

The recent growth of ethics literature in dentistry has been significant but is nearly 15 years behind medicine in terms of its analysis of dentally related ethical problems. Additionally, it is almost exclusively limited to journal articles, whereas hundreds of books have been written on themes of medical ethics. The complete range of ethical issues in dentistry and approaches to their resolution are thus yet well-defined. Still, there is a rising interest in ethics in dental education. As many as $80 \%$ of American dental schools ${ }^{5}$ and all dental hygiene schools ${ }^{6}$ now have courses in professional ethics. However, the ability of these courses to stimulated valid ethical reasoning seems questionable because the number of faculty with formal training in ethics is limited and, at least in dental schools, most of the courses are oriented toward jurisprudence.

\section{ETHICAL vs LEGAL}

Dental ethics is closely related to law. ${ }^{7,8}$ In many countries, there are laws that specify the way in which the dentist must deal with ethical problems occurring in the practice of the profession. Although law and ethics have similarities, law may be better defined as the sum total of rules and regulations by which a society is governed. Ethics, on the contrary, is informal or formal rule of behavior that guides individuals or groups of people. Legal rights are grounded in the law, and ethical rights are grounded in ethical principles and values.

Dental practitioners must be familiar with the legal aspects of the profession they practice, particularly because it may sometimes happen that the law and ethics conflict. In these cases, dentists must judge whether to obey the laws or principles of ethics, placing first the interest and well-being of the patient.

Dental ethics is a very wide and complex field of study, with many branches and subdivisions, which has developed its own specialized vocabulary, mainly structured on problems that are generated by the dental practice.
Dental ethics generated the publication of ethical codes that vary from one country to another, ${ }^{9}$ even if they have common features, such as dentist's obligations to place the patient's interests above his own, not to discriminate patients based on race, religion or other human rights, to protect patient confidentiality, etc.

In most countries, the dentistry associations are responsible for the development and application of the standards of ethics, ${ }^{10}$ which have a general character, that makes impossible to the dentist to solve any situation that he/she may encounter while practicing his/her job. The dental codes of ethics tried an international standardization materialized in guidelines for universities or authorities when they give dentists permission to practice or to offer private services. The principles contained in these codes reflect consensus about how the dentist must act. In 1997, The International Dental Federation ${ }^{11}$ adopted The International Principles of Ethics for the Profession of Dentist Everywhere, which must be considered as guidance by any dentist. These principles are not above the local and national traditions, laws or circumstances. According to these principles, the dentist must practice following the art and dental science, but also the principles of humanity.

\section{CODES OF PROFESSIONAL ETHICS}

In dentistry, like other branches of medicine, a set of principles contribute in establishing codes of ethics. These codes which are based on ethical principles, religious beliefs and the social and cultural considerations guide the dental practitioners in their everyday practice and also establish expectations for dentists in fulfilling their ethical and professional duties to the patients, public and the profession itself. These codes are as follows: ${ }^{12}$

1. Increasing ethical and professional consciousness and the sense of ethical responsibility.

2. Recognition of ethical issues by members and making a more informed ethical decision.

3. Establishing a standard for professional judgment and conduct.

4. Provide a statement of the ethical behavior that the public can expect from the member.

\section{ETHICAL PRINCIPLES}

Professional ethics in dentistry is based in the moral rule previously advanced, 'do your duty'. Ethics in dentistry derives from the role dentists assume in agreeing to enter into a relationship with patient, society and professional colleagues. In this relationship, dentists promise to 'do good' for society by employing their knowledge and skills in the pursuit of oral health for all. Six such duties can be delineated: To do good (beneficence), to do no harm 
(nonmaleficient), respect for autonomy, justice, veracity or truthfulness, confidentiality. ${ }^{1,13}$

\section{Duties and Obligation of Dentist an Individual Clinical Encounter (Patient)}

To achieve proper ethical conduct in a dental setting, dentists must first begin by treating each patient as an individual and take true interest in the patient's dental needs and wants. The major ethical principles that can guide in the performance of these duties are as follows:

a. To do good (beneficence): Beneficence is traditionally taken as the 'first principle' of morality and the dictum 'does well and avoid evil' lends some moral content to this principle. ${ }^{14}$ Beneficence denotes the practice of good deeds and it has a meaning of an obligation to benefit others or seek their good in itself. ${ }^{15}$ Beneficence as a principle of medical ethics is a duty, distinguishable and distinct from mercy, kindness or charity. ${ }^{16}$ It is essential that the dentist provides competent and timely dental care with the needs, desires and values of the patient given due consideration.

b. To do no harm (nonmaleficient): The term 'nonmaleficence' is derived from the ancient maxim 'premium non nocere' which is translated from Latin. It means 'first, do no harm ${ }^{17}$ Nonmaleficence essentially states that a dentist must not cause unnecessary harm to a patient. Obviously in some courses of treatment, some pain may be necessary to achieve the desired outcome; however, the decision regarding the level of pain that is acceptable to the patient must be determined by the patient.

c. Respect for autonomy: Autonomy is a term derived from Greek word Autos (self) and Nomos' (rule, governance or law) ${ }^{18}$ Autonomy refers to the right of the patient to determine what will be done with his or her own person. It also involves the patient's right to have confidentiality of his or her own medical history and records, and for the medical personnel to safeguard that right. The dentist must involve the patient in treatment decisions in a meaningful way, with due consideration being given to the patient's needs and desires. ${ }^{19}$

d. Justice: Dentists shall not refuse to accept patients into their practice or deny dental service to patients because of the patient's race, creed, color, sex, gender identity or national origin. ${ }^{19}$ Dentists must also avoid discriminating when making referrals to other dental professionals or in their hiring practices. According to Ozar and Sokol, the primary considerations when making referrals are the specialists' technical and communication skills, manner and philosophy of dental practice. ${ }^{3}$ e. Veracity or truthfulness: Veracity revolves around being truthful and respecting the position of trust that is essential in the dentist-patient relationship. This includes truthful communication without deception and maintaining intellectual integrity. Areas included under veracity are truthfulness in billing issues and advertising. It is unethical for a dentist to mark-up charges for procedures done to patients who may carry a particular insurance, or to recommend treatment that is unnecessary. ${ }^{20}$

f. Confidentiality: It is essential in order to obtain the patient's trust and it is a vital part of the codes of ethics all along the history, starting with the hippocratic oath. This ancient oath was amended by The Declaration from Geneva, ${ }^{21}$ which stipulates that the doctor will respect the secrets confided to him, even if the patient died.

The doctor-patient relationship is based on trust, so the dentists will not disclose to other people information about the patients without their permission and they must be aware of the fact that these duties extend to their staff too. The patient must be protected against any possible discrimination caused by the disclosure of personal information. A privilege of the dentist is to ask the patient confidential questions, but, at the same time, the doctor has the obligation to keep this information confidential.

\section{Duties and Obligation of Dentist toward Profession/Professional Colleagues}

The dental surgeons have to remember that the treatment and cure of the disease depends on the skill and prompt attention showed to the patient. The dentist has to be sober, courteous, sympathetic, helpful, modest and punctual.

Dentist should conduct professional activities and programs and develop leadership with their colleagues honestly, respectfully and with full responsibility.

\section{Duties and Obligation of Dentist toward Society}

Dentist should assume leadership in the community and should recognize and uphold the laws and regulations governing their profession. They should participate in dental health education of the public by promoting measures that improve the dental health of both the individual and the community.

\section{THE FUTURE PERSPECTIVES OF DENTAL ETHICS}

The future of dental ethics depends on the future of dentistry, the progress of science, so it is difficult to predict it. In principle, dental ethics should be flexible and open 
to change. Since dental practice involves many ethical challenges, physicians should be kept informed on the progress of the principles of dental ethics, which is in close relation with the technical aspects of this profession.

\section{CONCLUSION}

In any profession, when there are persistent failures by individuals to adhere to ethical standards, a code of ethics must be developed to guide the responsible behavior of its members. In short, dentistry is governed by a statutory self-regulating body. It is the responsibility of the body to ensure high ethical and legal standards for the dental profession. However, individual dentists have the responsibility to always act in the patient's best interest and to provide the highest standards of clinical care. They have the duty to provide confidentiality, to fully inform patients of procedures and to obtain the patient's consent prior to treatment.

\section{REFERENCES}

1. Peter S. Essentials of preventive and community dentistry. 2nd ed. New Delhi: Arya (Medi) Publishing House; 2005. p. 693.

2. Woodal L, Irene R. Legal, ethical and management aspects of the dental care system. 3rd ed. St Louis, Mosby-Year Book; 1987. p. 308.

3. Ozar, David T, Sokol, David J. Dental ethics at chairside: professional principles and practical applications. 2nd ed. Washington, DC: Georgetown University Press; 2002. p. 15-16.

4. Gale group. Encyclopedia of bioethics. 3rd ed. USA: Macmillan; 2003. p. 642-648.

5. Odom JG. The status of dental ethics instruction. J Dent Educ 1988;52(6):306-308.

6. Jong A, Heine CS. The teaching of ethics in the dental hygiene curriculum. J Dent Educ 1982;46(12):699-702.
7. Beemsterboer Ph L. Ethics and law in dental hygiene, 2nd ed. Philadelphia: WB Saunders; 2001. p. 148-149.

8. Welie JVM. Justice in oral health care: ethical and educational perspectives. 2nd ed. Milwaukee: Wis. Marquette University Press; 2006. p. 546.

9. American Dental Association, principles of ethics and code of professional conduct, with official advisory opinions revised to Jan 2005, Chicago: ADA; 2005.

10. Pyle M, Andrieu SC, Chadwick G, et al. ADEA commission on change and innovation in dental education. The case for change in dental education. J Dent Educ 2006;70(9):921-924.

11. FDI World. International principles of ethics for the dental profession. FDI World Dental Federation 1997;6(6):17.

12. Prasad DK, Hegde C, Jain A, Shetty M. Philosophy and ethics: its application in dental practice. J Educ Ethics Dent 2011;1(1): 2-6.

13. Nash DA. On ethics in the profession of dentistry and dental education. Eur J Dent Educ 2007;11(2):64-74.

14. Mahowald MB, Verp MS, Anderson RR. Genetic counseling: clinical and ethical challenges. Annu Rev Genet 1998 Dec;32: 547-559.

15. Cohen H, Locker D. The science and ethics of water fluoridation. J Can Dent Assoc 2001;67(10):578-580.

16. Miltone LC. Beneficence: honoring the commitment. Nurs Sci Q 2000;13(2):111-115.

17. Akabayashi A, Slingsby BT, Kai I, Nishimura T, Yamagishi A. The development of a brief and objective method for evaluating moral sensitivity and reasoning in medical students. BMC Med Ethics 2004;5:E1.

18. Holliday I, Ngok M, Yep R. A high degree of autonomy? Hong Kong special administrative region 1997-2002. The Political Quarterly 2002;73(4):455-464.

19. American Dental Association, council in ethics, bylaws and judicial affairs. Principles of Ethics and Code of Professional Conduct. Available at: http://www.ada.org/sections/about/ pdfs/ada_code.pdf.

20. Basic Information on Ethics in Dentistry. Available at: https:// www.dentallearning.org/course/...10/coursebook_FULL.pdf

21. Available at: http://www.wma.net./e/policy/c8.htm 